 \\ (11) PRODUCF̄ंO ONLINE REVISTA CIENTIFICA ELETRONICA DE ENGENHARIA DE PRODUCAO

\section{APLICAÇÃO DO DESDOBRAMENTO DA FUNÇÃO QUALIDADE PARA O DESENVOLVIMENTO DE VESTUÁRIO INFANTIL}

\section{APPLICATION OF QUALITY FUNCTION DEPLOYMENT FOR CHILDREN'S CLOTHING DEVELOPMENT}

\author{
Aline Cervi Imhof* E-mail: ali cervi@hotmail.com \\ Paulo Augusto Cauchick Miguel*E-mail: paulo.cauchick@ufsc.br \\ *Universidade Federal de Santa Catarina (UFSC), Florianópolis,SC, Brasil
}

\begin{abstract}
Resumo: Com os consumidores cada vez mais exigentes e a constante concorrência, as organizações necessitam aprimorar-se para atender as necessidades dos clientes. Neste contexto, encontram-se as indústrias têxteis e de vestuário, que tem sentido fortemente os efeitos da competição global, tendo que responder rapidamente às mudanças de estação e moda. $O$ Desdobramento da Função Qualidade (ou QFD - Quality Function Deployment) apresenta-se como um diferencial para o desenvolvimento de produtos, pois proporciona que as percepções da qualidade dos clientes estejam contidas no produto. Nesse sentido, o presente trabalho tem como objetivo demonstrar uma aplicação do QFD no desenvolvimento de vestuário infantil, visto a grande importância do setor têxtil e de vestuário na economia nacional, bem como a grande participação do segmento infantil nesse setor. Um modelo conceitual do QFD com quatro matrizes foi criado e aplicado para o desenvolvimento de uma peça de vestuário infantil. Os resultados da aplicação mostram a grande importância atribuída pelos clientes à segurança e ao conforto. As matrizes relacionaram as qualidades exigidas ao desenvolvimento da peça e do molde, as especificações técnicas das matérias-primas e aos parâmetros do processo de produção, mostrando a influência desses elementos na qualidade do produto final requerida pelo cliente. Concluiu-se que o modelo conceitual desenvolvido mostrou a relação das qualidades exigidas com as etapas de desenvolvimento e produção do produto. Finalmente, considera-se que aplicações desse tipo podem ser usadas em outros tipos de vestuário.
\end{abstract}

Palavras-chave: Desdobramento da função qualidade. QFD. Vestuário infantil.

Abstract: With the increasingly demanding consumers and constant competition, organizations need to improve to meet customer needs. In this context, textile and clothing companies have strongly felt the effects of global competition, having to quickly respond to seasonal and fashion changes. Quality function deployment is a method that can present a differential for product development. It provides that customer's perceptions of demanded quality are introduced in the product. In this sense, this paper aims to demonstrate an application of QFD in the development of children's clothing. This is a relevant industrial sector due to its great economic importance in the national economy in addition to the large participation of children's segment in this sector. A QFD conceptual model consisting of four matrices was developed and applied to the development of a piece of children's clothing. The application results showed the great importance given by customers to the safety and comfort requirements. The matrices related the demanded qualities to the development of the piece as well as the pattern, raw materials technical specifications, and parameters of the manufacturing processes, showing the influence of these quality elements in the final product quality required by the customer. It concludes that the conceptual model developed show a strong relationship of the demanded qualities in the stages of product development and manufacturing. Finally, such applications may be used in other types of garments.

Keywords: Quality function deployment. QFD. Children's clothing. 


\section{INTRODUÇÃO}

Com os clientes se tornando cada vez mais exigentes, é fundamental que as empresas consigam manter a lealdade e satisfação dos mesmos para permanecerem no mercado. No entanto, as organizações industriais se tornaram tão complexas que se criou uma distância entre a produção, desenvolvimento, marketing e clientes, dificultando para todas as funções da empresa ouvir a "voz do cliente" (LARGER, 2005). A fim de responder às necessidades dos clientes e obter vantagem competitiva, um método de tomada de decisão, o desdobramento da função qualidade (QFD) foi desenvolvido, integrando tecnologia, políticas organizacionais e exigências dos clientes (MEHRJERDI, 2010).

O desdobramento da função qualidade (QFD - Quality Function Deployment) tem sido amplamente usado como um método para realizar a tradução das exigências de clientes em características técnicas de projeto (CHAN; WU, 2002). É um método que gera melhoria e que permite que as empresas alcancem maiores níveis de qualidade (GOVERS, 2001). Assim, o QFD permite que as empresas, ao invés de tomar uma posição reativa, agindo sobre as reclamações dos clientes, se tornem pró-ativas para os problemas de qualidade, (BÜYÜKÖZKAN; ÇIFÇI, 2013).

No QFD, as atividades e operações da empresa são dirigidas pela voz do cliente (NAHM, 2013). Com isso, muitos benefícios podem ser obtidos através do QFD, tais como a compreensão das necessidades dos clientes, agregação de valor através da maximização da qualidade e satisfação do cliente, além de concepção de um sistema global da qualidade para atingir a satisfação do cliente e o desenvolvimento de estratégias que podem colocar uma empresa à frente da concorrência (MEHRJERDI, 2010).

Para garantir a qualidade de um produto, o mais importante é a definição dos requisitos que devem ser atendidos (AKAO, 1996). Segundo Govers (2001), o QFD permite que uma organização construa a qualidade do produto e controle o processo de desenvolvimento desde o conceito até as operações de fabricação, levando sistematicamente a voz do cliente para todos os níveis operacionais. O método tem feito com que as organizações considerem questões até então negligenciadas, sendo fundamental para conectar a voz do cliente com o projeto, trazendo informações que dão ao projetista uma compreensão muito melhor das 
necessidades dos usuários e do ambiente em que o produto está inserido (REVELLE et al., 1997).

Nesse contexto, encontra-se a indústria têxtil e de vestuário, que tem sofrido grandes mudanças em virtude da globalização, alta competitividade e concorrência de preços (BRUCE et al., 2004). May-Plumlee e Little (2006) destacam que as empresas de vestuário têm despendido esforços em desenvolver estratégias para o desenvolvimento de um produto orientado para o consumidor, porém, esses esforços não estão sendo efetivos na compreensão de como as informações dos consumidores podem ser obtidas e utilizadas no processo de desenvolvimento do produto.

O setor têxtil e de confecção mundial movimentou cerca de US\$ 744 bilhões em transações entre países (ABIT, 2015). O mapa da produção mundial começou a mudar na década de 80, saindo dos EUA, Europa e Japão para países emergentes da Ásia e, mais recentemente, Leste Europeu, Norte da África e Caribe, sendo a Ásia é responsável por $73 \%$ dos volumes totais produzidos no mundo (ABIT, 2015). O Brasil ocupa a quarta posição entre os maiores produtores mundiais de artigos de vestuário e a quinta posição entre os maiores produtores de manufaturas têxteis (ABIT, 2013). Considerando este cenário, os fabricantes precisam diferenciar seus produtos para manter seus clientes, fazendo com que a utilização do QFD para desenvolvimento de produtos têxteis e de vestuário torne-se uma vantagem a medida que trará as percepções da qualidade dos clientes para o produto, alcançando a satisfação do consumidor e, consequentemente, a sobrevivência da empresa no mercado.

No âmbito do setor de vestuário do país, o segmento de vestuário infantil representa quase um terço da produção brasileira, ficando atrás somente do segmento adulto feminino (41\%), cuja liderança pode ser atribuída ao alto volume de produção de artigos com vida útil curta (e.g. calcinhas e meias-calças) e à maior variedade de artigos consumidos (COSTA; ROCHA, 2009). Além da grande participação do vestuário infantil no mercado, no desenvolvimento de seus produtos são valorizadas características diversas de estética, que costumam ser evidenciadas em roupas de adultos, como as características funcionais.

Nesse contexto, o presente trabalho tem como objetivo demonstrar a aplicação do QFD no segmento de desenvolvimento de produtos têxteis, especificamente em vestuário infantil. Devido à sua eficácia no desenvolvimento de 
produtos e gestão da qualidade, muitas aplicações de QFD têm sido relatadas em grande variedade de produtos (CHAN; WU, 2002). No entanto, o uso do QFD no desenvolvimento de vestuário é escasso na literatura. Dessa forma, estudos a respeito do assunto tornam-se importantes para preencher essa lacuna e auxiliar estilistas no projeto de produtos que atendam às necessidades dos clientes.

\section{REFERENCIAL TEÓRICO}

O QFD foi concebido no Japão no final da década de 1960, dentro do contexto do Controle da Qualidade Total (TQC), como um método para desenvolvimento de novos produtos (AKAO; MAZUR, 2003; CHENG; MELO FILHO, 2007). A partir de 1983 foi introduzido nos EUA e Europa (AKAO; MAZUR, 2003), e, no Brasil, somente na década de 1990 (CARNEVALLI et al., 2004). O método tem sido vastamente utilizado em diversos países e atingiu um estágio em que é bem conhecido na literatura de gestão do desenvolvimento de produto (CHENG, 2003). A popularidade do método também pode ser reconhecida pela grande quantidade de publicações disponíveis sobre o tema (CHAN; WU, 2002).

Cheng e Melo Filho (2007, p.15) conceituam o QFD como "uma forma de comunicar sistematicamente a informação relacionada com a qualidade e de explicitar ordenadamente o trabalho relacionado com a obtenção da qualidade". O QFD é subdividido em Desdobramento da Qualidade (QD) e Desdobramento da Função Qualidade no sentido restrito (QFDr), tradução de narrowly defined QFD NDQFD. O QD utiliza a lógica de causa e efeito de forma estruturada e priorizada para desdobrar a qualidade e o QFDr é o desdobramento do trabalho, cujo objetivo é garantir que a qualidade seja cumprida pelas áreas funcionais da empresa integradamente (CHENG; MELO FILHO, 2007). Dessa forma, O QFD facilita a tradução da linguagem muitas vezes vaga dos clientes em uma "linguagem prática", que inclui simbologia, desenhos e instruções de trabalho (DEVADASAN et al., 2006).

No QD, o processo inicia com a formulação de um modelo conceitual, no qual relações entre tabelas geram matrizes, que por sua vez são combinadas relacionando os efeitos e os fatores causadores destes, sendo preenchidas com dados qualitativos e quantitativos (CHENG, 2003). Para que o QFD estreite a relação do cliente com o projetista, as características da qualidade do produto a ser projetado são estraídas a partir das qualidades exigidas pelos clientes (DIAS JR et 
al., 2012). Assim, a primeira matriz a ser estabelecida é a matriz da qualidade, que contém a qualidade planejada e a qualidade projetada para o produto, passando então para as outras matrizes que formam o modelo conceitual, permitindo visualizar as relações existentes entre os todos os componentes do processo de desenvolvimento com a qualidade projetada para o produto (CRISTIANO et al., 2000; CHENG; MELO FILHO, 2007). Os princípios do QFD não definem nenhum pré-requisito sobre os tipos de produtos ou serviços ou sobre o tipo de organização (CHAN; WU, 2002), como destacado na seção seguinte, voltada para sua aplicação no setor de vestuário.

\subsection{QFD no setor têxtil e de vestuário}

A Associação Brasileira da Indústria Têxtil e de Confecção (ABIT, 2015) enfatiza a importância econômica e social do setor têxtil e de confecção no Brasil, como sendo uma atividade com cerca de 200 anos no país e que atualmente representa quase $6 \%$ do valor total da produção da indústria de transformação, em que a indústria da moda é o segundo maior empregador e também o segundo maior gerador do primeiro emprego. Segundo a ABIT (2015), o Brasil está entre os oito maiores mercados consumidores de vestuário, cama, mesa e banho do mundo, sendo o que mais cresceu nos últimos dez anos.

A indústria têxtil e de vestuário tem características de mercado específicas, como o ciclo de vida de produtos mais curto, a alta volatilidade e a baixa previsibilidade (BRUCE et al., 2004), pois precisam responder rapidamente às mudanças da estação da moda e o valor agregado do produto decai rapidamente com o tempo (PITIMANEEYAKUL et al., 2004). Com esse cenário, desenvolver o produto de forma rápida e acertiva torna-se essencial para manter a vantagem competitiva da indústria.

Nesse setor, pode-se encontrar no mundo diversos exemplos de aplicação do QFD para desenvolvimento de calçados (BERGQUIST; ABEYSEKERA, 1996), vestimentas (HUANG; BERTAM, 2006; LIN et al., 2006; WAISARAYUTT; SIRITAWEECHAI, 2006; PARK, 2009; SORAK et al., 2015; VEZZETTI et al., 2015), tecidos (MOISESCU et al., 1999), bem como cama, mesa e banho (GÖNDÖR; PATAKI, 2008). O Quadro 1 sintetiza as publicações supracitadas com seus objetivos, ferramentas e métodos utilizados e principais resultados. 
Quadro 1 - Aplicações do QFD na Área Têxtil e de Vestuário

\begin{tabular}{|c|c|c|c|c|}
\hline Referência & Objetivo & Produto & $\begin{array}{l}\text { Matrizes e } \\
\text { ferramentas } \\
\text { adotadas }\end{array}$ & Principais resultados \\
\hline $\begin{array}{l}\text { Bergquist e } \\
\text { Abeysekera } \\
(1996)\end{array}$ & $\begin{array}{l}\text { Investigar as possibilidades da } \\
\text { utilização do QFD na área de } \\
\text { ergonomia }\end{array}$ & $\begin{array}{l}\text { Calçado de } \\
\text { segurança }\end{array}$ & Matriz da Qualidade & $\begin{array}{l}\text { Identificação das necessidades e exigências } \\
\text { humanas, complementando métodos } \\
\text { ergonômicos }\end{array}$ \\
\hline Moisescu et al. & $\begin{array}{l}\text { Estimar as características do tecido } \\
\text { através do QFD }\end{array}$ & Tecido & Matriz da Qualidade & $\begin{array}{l}\text { Estabelecimento dos requisitos tecnológicos e } \\
\text { funcionais do produto e a hierarquização das } \\
\text { características da qualidade }\end{array}$ \\
\hline $\begin{array}{l}\text { Huang e Bertram } \\
\text { (2006) }\end{array}$ & $\begin{array}{l}\text { Caracterizar os fatores-chave que } \\
\text { afetam o design e qualidade do } \\
\text { produto de vestuário }\end{array}$ & $\begin{array}{l}\text { Roupas de } \\
\text { Moda Popular } \\
\text { Feminina }\end{array}$ & $\begin{array}{l}\text { Método Delphi; } \\
\text { Matriz da Qualidade }\end{array}$ & $\begin{array}{l}\text { Percepção da importância do estudo de } \\
\text { mercado e seus desejos para a concepção de } \\
\text { um produto popular e identificação de } \\
\text { problemas de produção }\end{array}$ \\
\hline Lin et al. (2006) & $\begin{array}{l}\text { Propor um procedimento que ligue } \\
\text { os requisitos dos clientes com } \\
\text { características de projeto }\end{array}$ & $\begin{array}{l}\text { Roupas } \\
\text { funcionais }\end{array}$ & $\begin{array}{l}\text { Matriz da Qualidade; } \\
\text { AHP; ISM }\end{array}$ & $\begin{array}{l}\text { Identificação das características de projeto e } \\
\text { as necessidades dos clientes }\end{array}$ \\
\hline $\begin{array}{l}\text { Waisarayutt e } \\
\text { Siritaweechai } \\
\text { (2006) }\end{array}$ & $\begin{array}{l}\text { Mostrar o potencial do uso do QFD } \\
\text { como ferramenta de } \\
\text { desenvolvimento de produto }\end{array}$ & $\begin{array}{l}\text { Sutiã para } \\
\text { prática de } \\
\text { esportes }\end{array}$ & $\begin{array}{l}\text { Matriz da Qualidade; } \\
\text { Matriz de Matéria- } \\
\text { prima }\end{array}$ & $\begin{array}{l}\text { Percepção do QFD como uma ferramenta de } \\
\text { planejamento, comunicação e tomada de } \\
\text { decisão }\end{array}$ \\
\hline $\begin{array}{l}\text { Göndör e Pataki } \\
\text { (2008) }\end{array}$ & $\begin{array}{l}\text { Desenvolver um método de projeto } \\
\text { de produto que considere o ciclo de } \\
\text { vida completo do produto }\end{array}$ & $\begin{array}{l}\text { Cortinas, roupa } \\
\text { de cama, } \\
\text { colchas, } \\
\text { estofados }\end{array}$ & $\begin{array}{l}\text { Matriz da Qualidade; } \\
\text { Método Harrington }\end{array}$ & $\begin{array}{l}\text { Implementação do método de projeto de } \\
\text { produto com alto grau de inovação }\end{array}$ \\
\hline Park (2009) & $\begin{array}{l}\text { Explorar a aplicabilidade do QFD no } \\
\text { desenvolvimento de produtos de } \\
\text { roupas }\end{array}$ & Roupas sociais & $\begin{array}{l}\text { Matriz da Qualidade; } \\
\text { Método Lyman }\end{array}$ & $\begin{array}{l}\text { Identificação das necessidades dos clientes e } \\
\text { tradução em atributos para o projeto do } \\
\text { produto }\end{array}$ \\
\hline $\begin{array}{l}\text { Sorak et al. } \\
(2015)\end{array}$ & $\begin{array}{l}\text { Desenvolver um método para } \\
\text { melhoria de produtos e processos }\end{array}$ & Lingerie & $\begin{array}{l}\text { Matriz da Qualidade; } \\
\text { Benchmarking }\end{array}$ & $\begin{array}{l}\text { Identificação e revisão das características } \\
\text { essenciais dos produtos e processos para } \\
\text { melhorá-los }\end{array}$ \\
\hline $\begin{array}{l}\text { Vezzetti et al. } \\
\text { (2015) }\end{array}$ & $\begin{array}{l}\text { Demonstrar como o uso do } \\
\text { gerenciamento do ciclo de vida do } \\
\text { produto no segmento têxtil pode ser } \\
\text { útil. }\end{array}$ & $\begin{array}{l}\text { Roupas de } \\
\text { Moda Feminina }\end{array}$ & $\begin{array}{l}\text { Matriz da Qualidade; } \\
\text { AHP; Análise do } \\
\text { Ciclo de Vida }\end{array}$ & $\begin{array}{l}\text { Quantificação do impacto que o processo de } \\
\text { gerenciamento do cliclo de vida tem no } \\
\text { processo lançamento de novos produtos }\end{array}$ \\
\hline
\end{tabular}

Fonte: elaborado pelos autores com base na busca e organização bibliográfica 
Observa-se que as publicações tiveram uma abordagem empírica, fazendo uma aplicação do QFD no desenvolvimento de determinado produto. De fato, o uso do método tem sido majoritariamente mais aplicado para o desenvolvimento de produtos tangíveis, mesmo sendo um método flexível, que pode ser usado no desenvolvimento de processos, serviços, softwares, entre outros (CRISTIANO et al., 2000; CARNEVALLI et al., 2004).

Métodos e ferramentas utilizados em conjunto com o QFD foram o Método Delphi, Análise Hierárquica (AHP), Técnica Interpretativa de Modelação Estrutural (ISM), Método Harrington e Método Lyman. Destaca-se que os artigos cujo objetivo era desenvolver uma proposta ou procedimento para o projeto de produto combinaram o QFD com um ou mais destes métodos. Os estudos que somente fizeram a aplicação do QFD sem desenvolver proposta, em sua maioria, não adotaram outra ferramenta ou método. Cristiano et al. (2000) analisaram o uso do QFD em empresas do Japão e EUA no passado, e também identificaram o uso de ferramentas adicionais ao QFD.

A maior parte das publicações sobre QFD no setor industrial estudado é restrita ao uso da primeira matriz - matriz da qualidade - para obtenção dos requisitos e necessidades dos clientes. A única exceção é o estudo de Waisarayutt e Siritaweechai (2006), no qual os autores utilizam, além da matriz da qualidade, a matriz de matéria-prima (características da qualidade $\mathrm{x}$ características da matériaprima). Na realidade, apesar da flexibilidade de aplicação do método, a maioria dos estudos tem limitado o uso do QFD à elaboração da matriz da qualidade, porém, além de limitar os seus resultados, essa situação pode estar influenciando os usuários do QFD a não considerarem as outras matrizes ao aplicar o método (CARNEVALLI; CAUCHICK MIGUEL, 2007). Mesmo no início da aplicação do QFD, o trabalho de Cristiano et al. (2000) já apontava que a maioria das aplicações nos EUA restringiam-se a fase do desdobramento da qualidade, pouco mais de um terço utilizavam a fase do desdobramento dos requisitos do produto em especificações de engenharia e poucas aplicações abrangiam a fase de relacionar o produto com os requisitos do processo. Souza e Cauchick Miguel (2017) destacam em estudo sobre - QFD no setor de serviços que, tanto a profundidade de aplicação quanto a conceituação do QFD, na maioria das vezes, ficam restritas à primeira matriz, e os desdobramentos de matrizes que visam planejar as operações e processos 
decorrentes da primeira matriz ainda é algo pouco recorrente e, muitas vezes, sequer citada como parte do método.

No setor de vestuário, Huang e Bertram (2006) afirmam que os requisitos da qualidade dos consumidores diferem dos fatores considerados importantes pelos estilistas, o que faz com que esses devam alinhar seus instintos no momento de projetar com as preocupações dos consumidores, preenchendo essa lacuna. Embora seja possível alcançar benefícios substanciais implementando apenas a matriz da qualidade, os maiores ganhos, no entanto, são obtidos quando a "voz do cliente" começa a ser introduzida para o nível mais detalhado de operações de fabricação (GOVERS, 2001). O uso de um modelo conceitual do QFD para desenvolvimento de um produto de vestuário vem atender à necessidade de compreensão dos requisitos de qualidade dos clientes, pelos estilistas, bem como se apresenta como um método estruturado para o desenvolvimento do projeto do produto, uma vez que as relações entre a qualidade projetada para o produto e os componentes do processo serão visualizadas.

\section{PROCEDIMENTOS METODOLÓGICOS DE PESQUISA}

O trabalho foi dividido em quatro etapas, em que a primeira etapa consistiu na realização da busca bibliográfica, especificamente de artigos em periódicos que utilizaram o QFD para desenvolver algum produto têxtil ou de vestuário, anteriormente discutidos. Para identificar e localizar essas publicações, foram consultadas as seguintes bases de dados: Web of Science, Scopus, Scielo, Ebsco, Emerald, Wiley e Compendex. Na realização da busca, utilizou-se como palavraschave o termos "QFD”, "Quality Function Deployment", "house of quality" combinados com "apparel", "clothing", "garment", "textile". As publicações resultantes foram consideradas até $\mathrm{O}$ ano de 2016. O software Endnote $\AA$ foi utilizado para armazenar e organizar os artigos. Foram identificados 46 trabalhos, dos quais nove estavam em duplicidade e três consistiam em anais de congressos (descartados). Entretanto, após a leitura dos resumos e palavras-chave, verificou-se que 23 artigos estavam fora do escopo do presente trabalho, sendo selecionados 11 artigos para análise. Destes, 10 estavam disponíveis e foram analisados, conforme apresentado no Quadro 1.

O propósito da segunda etapa foi identificar as oportunidades de melhoria 
para utilização do QFD no segmento têxtil e de vestuário. Para isso, os 10 artigos foram analisados quanto ao grau de aplicação do QFD e concluiu-se que, majoritariamente, o método só é utilizado até a primeira matriz (matriz da qualidade). Dessa forma, percebeu-se a necessidade de aprimorar essa aplicação com um uso mais amplo do método, considerando o modelo conceitual, a fim de proporcionar, além da percepção das necessidades dos clientes, uma visão de como essas exigências se relacionam com as demais fases de concepção do produto.

Sendo assim, a terceira etapa compreendeu o desenvolvimento de um modelo conceitual aplicável ao desenvolvimento de uma peça de vestuário infantil, o qual contempla as quatro matrizes, ilustradas na Figura 1.

Figura1 - Modelo conceitual para vestuário infantil

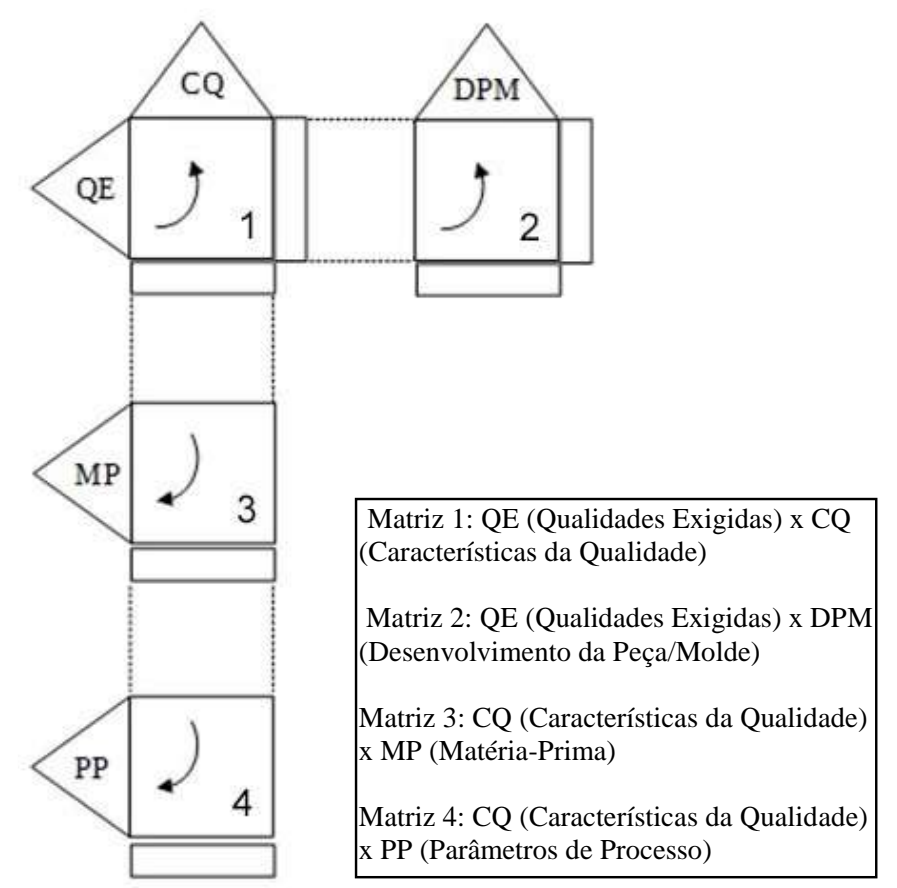

Por fim, a quarta etapa consistiu na aplicação do modelo conceitual proposto no desenvolvimento de um vestuário infantil tipo body em 100\% algodão. Inicialmente, seguindo a orientação de Cheng e Melo Filho (2007), que sugerem de 20 a 30 entrevistas individuais, 28 mães cujos filhos tem de 0 a 2 anos, responderam a uma pergunta aberta: quais características você considera importante que haja na roupa a comprar para seu filho? Coletadas todas as respostas, um diagrama em árvore de dois níveis foi elaborado para detalhar as qualidades exigidas (ver Apêndice A). Posteriormente, o grau de importância de cada qualidade foi avaliado pelas clientes, atribuindo notas de 1 a 5 a cada item (sendo 1 o menos importante e 
5 o de maior importância). Os valores apresentados na coluna de grau de importância da matriz da qualidade são a moda, ou seja, valor mais repedido, dos valores obtidos com as entrevistadas.

Para determinar as características da qualidade relacionadas às qualidades exigidas foram consultados especialistas da área, bem como para avaliar o grau de relação entre elas e coletar informações sobre o processo de manufatura. $O$ grau de influência foi definido como 9 para uma relação forte, 3 para moderada e 1 para relação fraca. As células em branco significam que não há relação. No próximo item serão apresentados os resultados da aplicação do modelo conceitual e sua análise.

\section{RESULTADOS E DISCUSSÃO}

O modelo conceitual proposto é composto por quatro matrizes (Figura 1). 0 modelo foi então aplicado no desenvolvimento de um body, peça infantil amplamente utilizada, pois tem a função de proteger as costas e peito do bebê mantendo sua temperatura, além de não se deslocar quando o bebê se movimenta, já que é abotoado abaixo da fralda, sendo usado como blusa ou por baixo de outras peças.

O método QFD possibilita estruturar e quantificar conceitos abstratos dos clientes referentes a qualidade (GODOY et al., 2013). A primeira matriz (Figura 2) mostra que os aspectos considerados mais importantes pelos clientes são os relacionados a "segurança" e "conforto". Esse resultado enfatiza a relevância em a roupa possibilitar conforto para a criança e não the oferecer nenhum risco. Apesar de o crescimento nessa faixa etária ser rápido, verifica-se que os clientes desejam roupas que mantenham sua qualidade após o uso e lavagem, ou seja, sejam duráveis. Os aspectos de facilidade de uso da vestimenta são relevantes, porém, é possível concluir que foi atribuído um grau de importância mais baixo pelo fato da maioria das peças de roupa já considerarem esses quesitos, sendo um parâmetro já esperado. Por fim, os itens de beleza são os menos importantes, mostrando que a influência da moda para o vestuário infantil não é tão relevante quanto para 0 vestuário adulto, especialmente o feminino. 
Figura 2 - Matriz 1: Qualidades Exigidas x Características da Qualidade

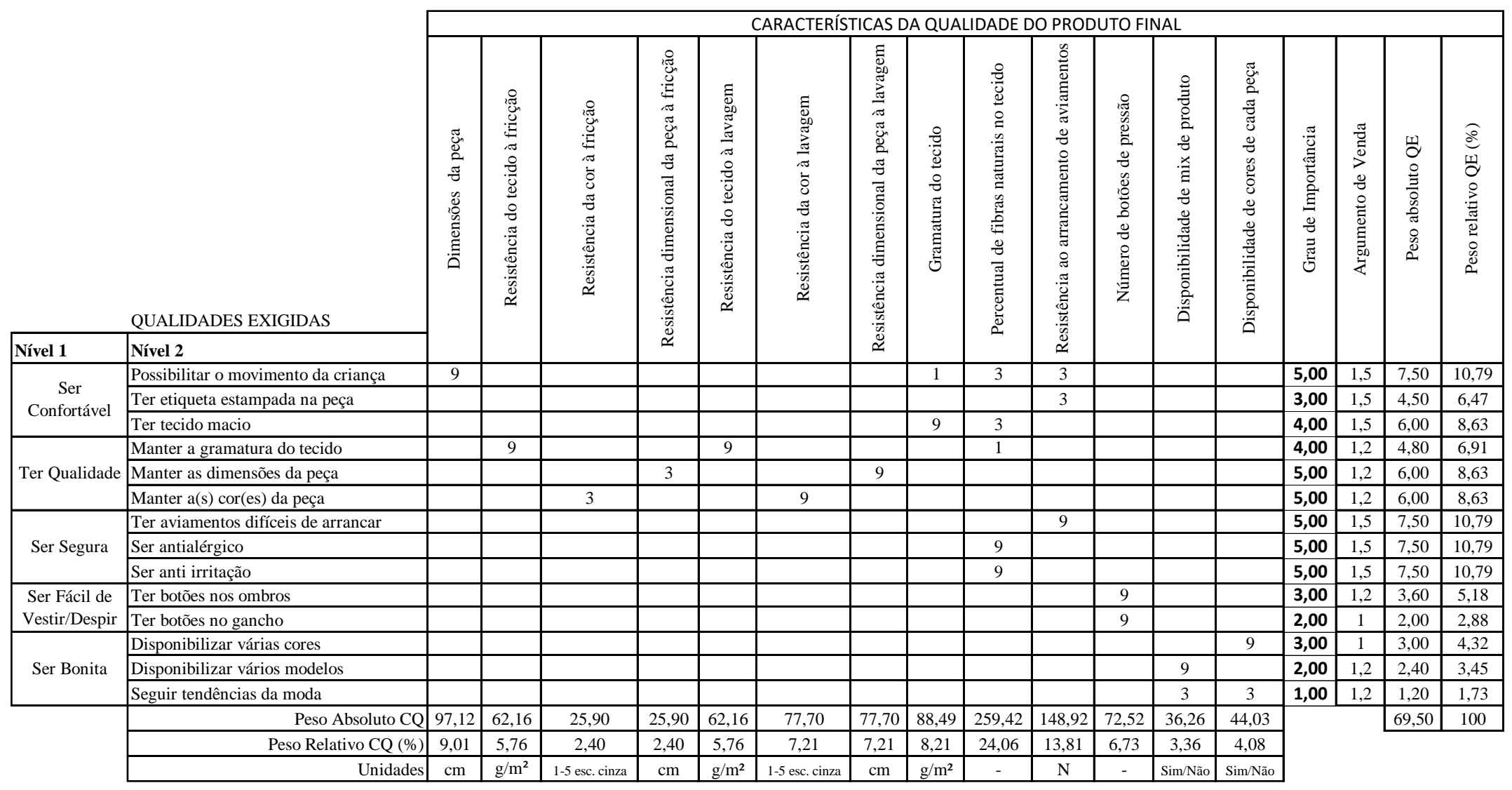


Waisarayutt e Siritaweechai (2006) enfatizam que, ao contrário de produto alimentar, o produto de vestuário é uma mercadoria de grande envolvimento com o usuário, que pode ser notado por meio de várias características relevantes como, por exemplo, a função, expressão e estética, sendo necessário que o produto integre todos esses aspectos, a fim de satisfazer o cliente. Essas relações interativas com o usuário fizeram com que a indústria de vestuário passasse de uma fabricação orientada para o produto para orientada para o consumidor, tornando as operações da indústria profundamente influenciadas pelo comportamento do consumidor (HUANG; BERTRAM, 2006). Nesse aspecto, o uso do QFD para a indústria de vestuário vem ao encontro da necessidade de contemplar os desejos do consumidor, visto seu envolvimento com o produto.

Além da matriz da qualidade (Figura 2), uma segunda matriz se relaciona com as qualidades exigidas, na qual são desenvolvidos o modelo da peça e os moldes para o corte do tecido. A segunda matriz (Figura 3) indica que a possibilidade de execução dos movimentos, seguido da análise da composição do tecido e desenvolvimento do modelo são os aspectos de maior interferência no atendimento às qualidade exigidas do produto. 
Figura 3 - Matriz 2: Qualidades Exigidas x Desenvolvimento da Peça/Molde

\begin{tabular}{|c|c|c|c|c|c|c|c|c|c|c|c|c|c|}
\hline \multirow[b]{2}{*}{ QUALIDADES EXIGIDAS } & \multicolumn{13}{|c|}{ DESENVOLVIMENTO DA PEÇA/MOLDE } \\
\hline & 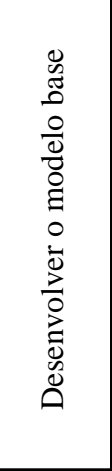 & 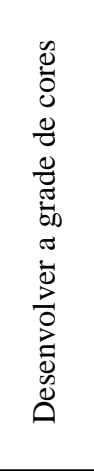 & 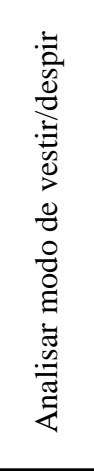 & 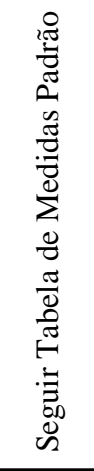 & 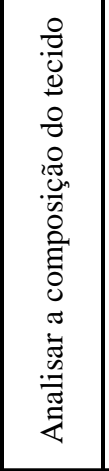 & 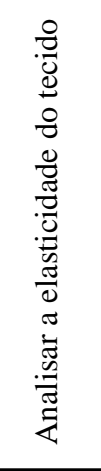 & 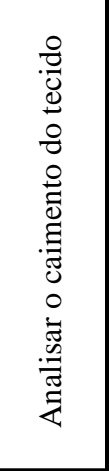 & 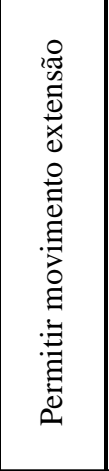 & 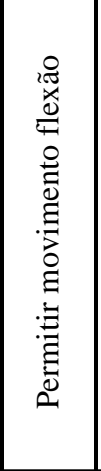 & 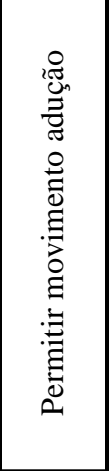 & 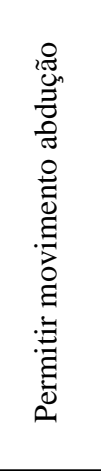 & 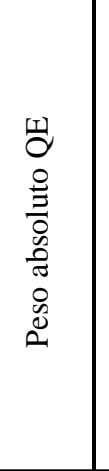 & 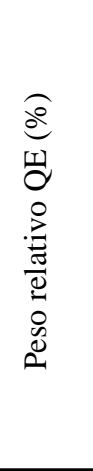 \\
\hline Possibilitar o movimento da criança & 9 & & 1 & 9 & & 3 & 3 & 9 & 9 & 9 & 9 & 7,50 & 10,79 \\
\hline Ter etiqueta estampada na peça & 3 & & & & & & & & & & & 4,50 & 6,47 \\
\hline Ter tecido macio & & & & & 3 & 3 & 3 & & & & & 6,00 & 8,63 \\
\hline Manter a gramatura do tecido & & & & & 3 & 3 & 3 & & & & & 4,80 & 6,91 \\
\hline Manter as dimensões da peça & & & & & 3 & 3 & 3 & & & & & 6,00 & 8,63 \\
\hline Manter a(s) cor(es) da peça & & & & & 1 & & & & & & & 6,00 & 8,63 \\
\hline Ter aviamentos difíceis de arrancar & 9 & & & & & & & & & & & 7,50 & 10,79 \\
\hline Ser antialérgico & & & & & 9 & & & & & & & 7,50 & 10,79 \\
\hline Ser anti irritação & & & & & 9 & & & & & & & 7,50 & 10,79 \\
\hline Ter botões nos ombros & & & 9 & & & & & & & & & 3,60 & 5,18 \\
\hline Ter botões no gancho & & & 9 & & & & & & & & & 2,00 & 2,88 \\
\hline Disponibilizar várias cores & & 9 & & & & & & & & & & 3,00 & 4,32 \\
\hline Disponibilizar vários modelos & 3 & & & & & & & & & & & 2,40 & 3,45 \\
\hline Seguir tendências da moda & 3 & 3 & & & & & & & & & & 1,20 & 1,73 \\
\hline Peso Absoluto CQ & 159,30 & 30,60 & 57,90 & 67,50 & 191,40 & 72,90 & 72,90 & 67,50 & 67,50 & 67,50 & 67,50 & 68,06 & 100 \\
\hline Peso Relativo CQ (\%) & 17,27 & 3,32 & 6,28 & 7,32 & 20,75 & 7,90 & 7,90 & 7,32 & 7,32 & 7,32 & 7,32 & & \\
\hline
\end{tabular}

Revista Produção Online. Florianópolis, SC, v.17, n. 4, p. 1134-1159, 2017. 
Os movimentos dos membros são classificados como extensão, flexão, abdução e adução, que consistem nos movimentos característicos dos bebês. $O$ segundo item mais representativo, relativo à composição do tecido, remete além do conforto e durabilidade da peça, principalmente à questões de saúde, devendo ser anti irritação e antialérgico. Por fim, a criação do modelo base deve considerar a necessidade de movimentação e segurança do bebê, e a partir do modelo base, são criados modelos diferenciados através de estampas, adereços, etc. Nota-se que esses três itens de maior relevância ficam à cargo dos estilistas, pois são os responsáveis em criar o modelo e escolher o tecido. Dessa forma, enfatiza-se a importância em haver uma ampla compreensão pelos estilitas dos requisitos demandados pelos clientes, de modo que possam desenvolver peças que satisfaçam à essas necessidades. Vários métodos existentes para o desenvolvimento de produtos dependem de uma cooperação entre o projetista e o usuário, porém, no QFD, as necessidades do usuário são mapeados e integrados ao desenvolvimento do produto e ao processo (BERGQUIST; ABEYSEKERA, 1996). Assim, uma vez que na indústria de vestuário os produtos são criados pelos estilistas, é fundamental que esses considerem as necessidades dos usuários, desenvolvendo produtos com maior aceitação no mercado.

Os diversos tipos de tecidos apresentam singularidades relativas à sua estrutura e às matérias-primas com as quais são produzidos, que devem ser observadas pelo modelista para adequação ao produto que se quer obter. $\mathrm{O}$ grau de elasticidade e caimento são as especificidades dos tecidos que mais influenciam na elaboração do molde. Dessa forma, é imprescindível a análise desses elementos para que a peça seja modelada corretamente, proporcionando conforto e permitindo a execução de todos os movimentos da criança. Copeland et al. (2009) enfatiza que vestimentas inadequadas se tornam um obstáculo às atividades físicas das crianças.

Em relação às dimensões do produto é aconselhável que se siga a tabela de medidas padrão, cuja norma está em vigor desde dezembro de 2009 (ABNT NBR 15800:2009). Essa norma tem sido amplamente utilizada pois estabelece uma indicação de medidas corporais de bebês, crianças e adolescentes, auxiliando no desenvolvimento e padronização de vestuário desse segmento.

Percebe-se que o setores de criação e modelagem, numa confeccção infantil, tem grande interferência na qualidade do produto final, pois é onde são avaliados e definidos muitos dos requisitos que podem conferir qualidade à peça. Uma prática 
comum em confecções é a realização de testes de prova da peça piloto, a fim de verificar questões de modo de vestir e despir e execução de movimentos. Um produto de alta qualidade pode ser considerado como um produto adaptado às capacidades e limitações humanas, portanto, um produto ergonômico (BERGQUIST; ABEYSEKERA, 1996). Durante o teste da peça piloto é possível identificar se as qualidades exigidas pelos clientes, identificadas pelo QFD, foram contempladas durante a criação e execução da peça.

A matriz de matéria-prima (matriz 3 , mostrada na Figura 4) relaciona as características da qualidade com as características do tecido - matéria-prima principal na fabricação de vestuário, e com os aviamentos. Com relação ao tecido, o percentual de fibras sintéticas é o elemento que mais influencia na sua qualidade, seguido dos percentuais de alteração de gramatura e dimensão, características relacionadas à durabilidade. Essas especificações técnicas do tecido são de grande relevância, já que a escolha do tecido para a confecção da peça é uma das primeiras decisões a serem tomadas após o desenho do modelo.

Em artigos infantis, a composição das fibras é de suma importância, a fim de que proporcione conforto, não cause alergia e irritações de pele, sendo mais indicado o uso de tecidos compostos por fibras naturais. A gramatura do tecido está fortemente relacionada à maciez pois, de modo geral, quanto maior for a gramatura, mais macio será o tecido. A lavagem e a fricção são as operações que podem diminuir a gramatura do tecido, alterar a cor e as dimensões da peça.

Em relação aos aviamentos desse modelo de body, foram listados a linha de costura, o laço decorativo e os botões de pressão. A linha precisa ter uma tenacidade mínima de 36 e alongamento não inferior a 17\%, para que a costura da peça não arrebente facilmente ao movimento do bebê e também para auxiliar na resistência ao arrancamento dos enfeites costurados. De acordo com a norma ABNT NBR 16365:2015, a circunferência e as extremidades livres dos laços decorativos não podem exceder $75 \mathrm{~mm}$. Os botões devem ser aplicados em uma quantidade mínima de 6 unidades para facilitar $o$ ato de vestir e despir. 
Figura 4 - Matriz 3: Características da Qualidade x Matérias-Primas

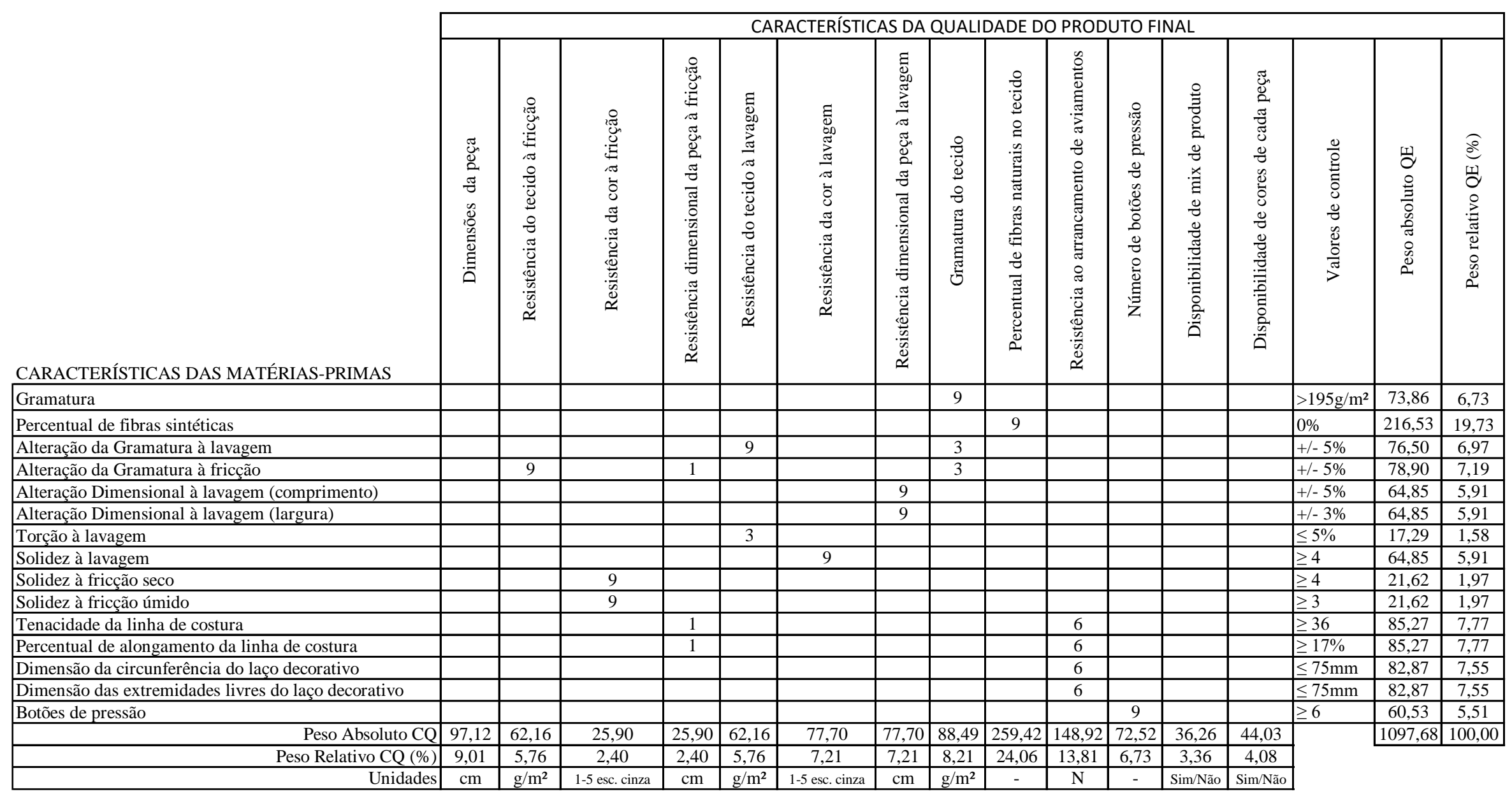

Revista Produção Online. Florianópolis, SC, v.17, n. 4, p. 1134-1159, 2017. 
A matriz de matérias-primas lista as especificações técnicas dos materiais para 0 produto. Ter essas características definidas auxilia o desenvolvedor na pesquisa de materiais, além de proporcionar uma diminuição no tempo de desenvolvimento (WAISARAYUTT; SIRITAWEECHAI, 2006).

A quarta matriz (Figura 5) inclui as características da qualidade e os parâmetros do processo. O resultado dessa matriz mostra que a resistência da costura dos aviamentos, característica ligada à segurança da roupa, é o fator mais relevante. Esse item indica que a costura deve ser feita de modo que suporte uma força mínima de $70 \mathrm{~N}$. O descanse dos tecidos é muito importante pois são comercializados em rolos, onde ficam tensionados. Com isso, é preciso esticá-los e deixá-los descansar por um tempo pré-determinado antes de realizar o corte, a fim de retornarem à sua condição inicial. Caso essa etapa não seja executada corretamente, é possível que haja problema de encolhimento, diminuindo as dimensões da peça. Posicionar o molde no fio, ou seja, paralelo à ourela, evita que a peça fique com as costuras desalinhadas no corpo. As alterações dimensionais tanto no corte quanto na costura devem ter tolerâncias baixas, pois é fundamental que o produto final esteja dentro das medidas determinadas na modelagem. 
Figura 5 - Matriz 4: Características da Qualidade x Parâmetros de Processo

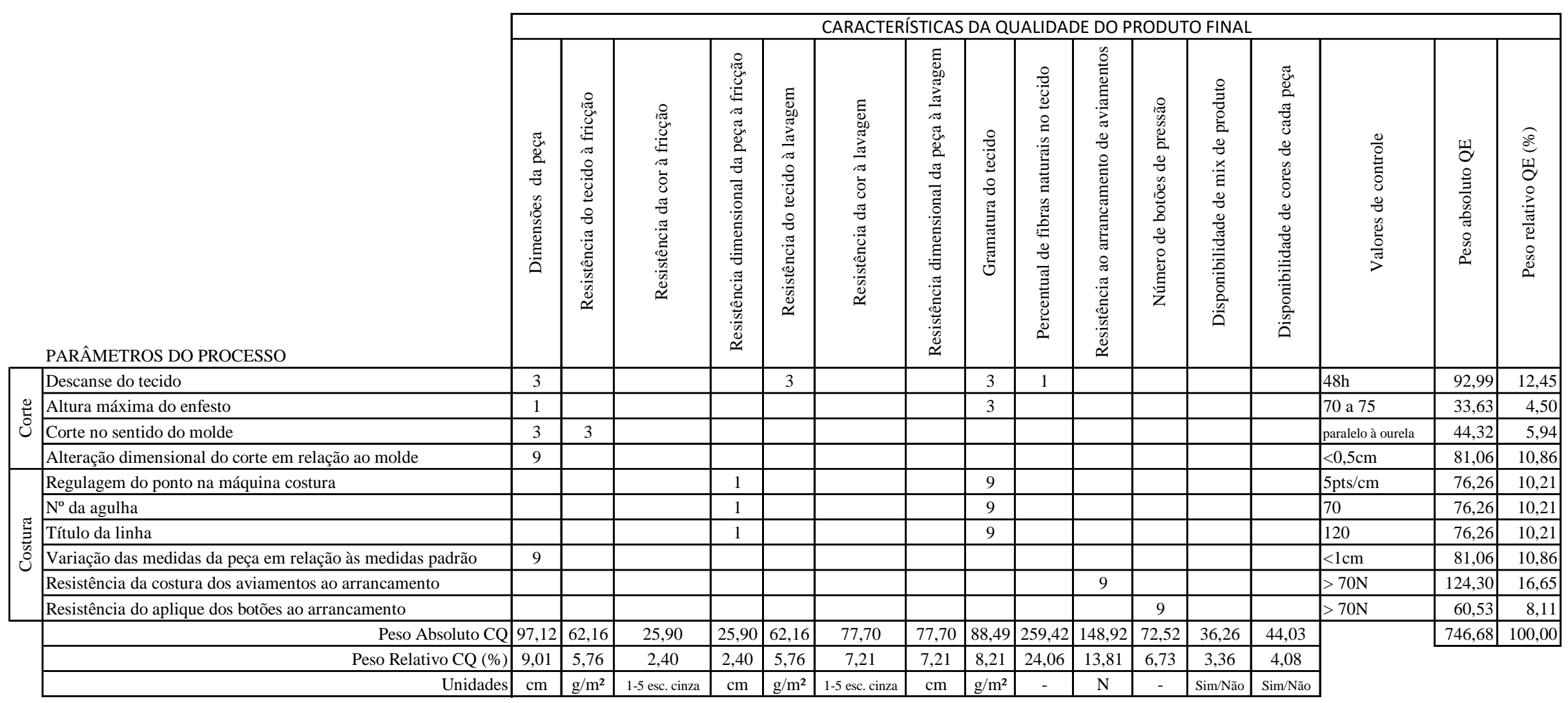

Revista Produção Online. Florianópolis, SC, v.17, n. 4, p. 1134-1159, 2017. 
No vestuário infantil existe uma grande preocupação com a segurança das roupas. Por exemplo, os aviamentos não devem ser facilmente arrancados, zíperes não devem ter orifícios no puxador, cordões têm um tamanho pré-determinado. Esses riscos físicos são abordados em norma lançada recentemente no Brasil (ABNT NBR 16365, 2015), que entrou em vigor em 24 de maio de 2015. A norma afirma que crianças até os cinco anos não tem noção dos riscos e não sabem como reagir a uma situação de perigo, por isso, as roupas precisam oferecer segurança e nenhum risco oculto a elas. Nesse sentido, ter aviamentos difíceis de arrancar, além de promover a segurança, faz com que esses aviamentos não limitem os movimentos ou tranquem em algum objeto, evitando acidentes.

O modelo conceitual focou em uma peça específica de roupa infantil, o body em tecido $100 \%$ algodão, porém por similaridade considera-se que esse modelo pode ser aplicado a outros tipos de peça, tais como camisetas, macacões, calças e vestidos, fazendo adequações dos parâmetros, se necessário, pois as etapas de criação e produção são muito similares. Uma limitação da pesquisa é que, mesmo consultando especialistas na área, essa aplicação do QFD foi realizada por meio de uma simulação. Dessa forma, os valores contidos nas matrizes são valores de referência, mas advém de dados próximos do real.

O QFD permite identificar influências, definir objetivos e controlar o processo, para que o produto final atenda às qualidades exigidas pelo cliente. $O$ método é muito útil devido ao fato de que promove uma forma sistemática de pensar onde todas as exigências do usuário são confrontadas com todas as características do produto (BERGQUIST; ABEYSEKERA, 1996). Dessa forma, o método QFD fornece informações relevantes ao processo decisório, por evidenciar as exigências e elementos de qualidade e possibilitar uma ampla visibilidade dos fatores que afetam a qualidade (GODOY et al., 2013).

No entanto, usando apenas a matriz da qualidade, como tem sido feito majoritariamente, pode-se conhecer os requisitos de maior importância sob o ponto de vista do cliente, porém, não se consegue visualizar como esses requisitos se relacionam com os demais itens que resultam no produto final, nem como controlar o processo de forma a garantir a satisfação do cliente. Além disso, uma empresa pode identificar deficiências nos processos através das demais matrizes ao aplicar desdobramento da função qualidade (HUANG; BERTAM, 2006). Oke (2013) reforça que os processos de planejamento do processo e o planejamento de produto 
precisam de mais estudos através do método QFD, pois o método pode ser central para programas de melhoria da qualidade, contudo, parece não ser claramente entendido e às vezes aplicado incorretamente.

O QFD é um método eficaz de planejamento da qualidade pelo fato de fornecer um diagnóstico da realidade, priorizando as direções importantes que oferecem um potencial de melhoria de acordo com o desejo dos clientes (GODOY et al., 2013). Ao utilizar um modelo conceitual com vários desdobramentos das matrizes no desenvolvimento de vestuário, os parâmetros dos processos e dos insumos que estão relacionados às qualidades exigidas pelos clientes são identificados e priorizados. Assim, o setor da qualidade pode concentrar esforços nos parâmetros mais relevantes, contribuindo para garantia da qualidade, cujos requisitos foram definidos pelo próprio cliente.

$\mathrm{Na}$ indústria têxtil, as empresas estão trabalhando para desenvolverm novos produtos cada vez mais rápido, aumentando a frequência com que os produtos são lançados no mercado (VEZZETTI et al., 2015). Nesse cenário com crescente oferta, os produtos só serão aceitos se estiverem adequados as exigências dos clientes. Dessa forma, O QFD vem a contribuir substancialmente para que os produtos lançados tenham sucesso no mercado.

\section{CONCLUSÕES}

O vestuário infantil é um segmento de grande participação na produção nacional. É fundamental que as empresas desse âmbito desenvolvam produtos baseados no ponto de vista dos clientes, criando um diferencial, pois, como destaca a literatura, os clientes têm se tornado cada vez mais exigentes, buscando produtos que contenham suas percepções da qualidade. Nesse cenário, conhecer quais são as qualidades exigidas bem como seu grau de importância de modo a garantir que estejam presentes no produto final torna-se imprescindível para alcançar a satisfação do cliente e reforçar a capacidade de concorrência da empresa no mercado.

O objetivo desse estudo foi demonstrar uma aplicação do modelo conceitual do QFD para o desenvolvimento de vestuário infantil, onde o desenvolvimento de um body infantil foi apresentado. Não foram encontrados na literatura consultada estudos que utilizaram o QFD para desenvolver produtos similares (vestuário infantil) 
e os que desenvolveram outros tipos de vestuário, em sua maioria, não contemplaram as demais matrizes do QFD.

Nesse sentido, viu-se necessário propor uma aplicação mais ampla do QFD, a fim de demonstrar como as exigências dos clientes se relacionam com os demais elementos que compõe o desenvolvimento e produção de produtos dessa natureza. O QFD proporciona a tradução da voz do cliente para o processo de desenvolvimento de produto, possibilitando um estreitamento da relação entre os estilistas e os clientes, identificando suas qualidades exigidas, ligando-as com as características do produto, matéria-prima e processo. A análise do QFD revelou que as características relacionadas ao conforto e à segurança são as consideradas mais importantes pelos clientes consultados, mas os mesmos também desejam que a peça seja durável. Essas características são observadas nas etapas de desenvolvimento e produção da peça, apresentadas pelas matrizes.

O estilista deve desenvolver um modelo que permita a execução dos movimentos e escolher um tecido com gramatura que proporcione maciez, conforme revelado nos resultados. Além disso, o quesito de segurança aparece principalmente ao analisar a composição do tecido para que não cause alergia ou irritação. A durabilidade será atendida pelo modelista, que fará a análise do caimento e elasticidade do tecido para a confecção do molde. A gramatura do tecido é o elemento que garante o conforto, enquanto o percentual fibras sintéticas, tamanho do enfeite, tenacidade e alongamento da linha de costura conferem segurança à peça. A resistência à alteração da gramatura, dimensão e cor do tecido durante a lavação e fricção asseguram durabilidade à roupa. Por fim, considerando os parâmetros de processos, o descanse do tecido, corte no sentido do molde e fidelidade às medidas da peça vão contribuir para o conforto, enquanto a resistência da costura dos enfeites proporcionará segurança e a regulagem do ponto e título da linha estão relacionadas à durabilidade. Dessa forma, o modelo conceitual de quatro matrizes mostrou, além da interação das exigências dos clientes com as características do produto, que a etapa de desenvolvimento da peça e molde, as especificações técnicas das matérias-primas e os parâmetros de processo exercem forte influência na qualidade do produto final requerida pelo cliente.

O modelo conceitual desenvolvido neste estudo foi específico para uma peça do vestuário infantil. Embora este tenha suas peculiaridades, acredita-se que este modelo conceitual pode ser usado para o desenvolvimento de outros tipos de 
vestuário, cujo processo de desenvolvimento e fabricação seja similar. Sendo assim, esta aplicação do QFD pode contribuir para aplicação do método ao desenvolvimento de outras vestimentas, tanto no vestuário infantil quanto em outros segmentos. A limitação do estudo consistiu em não ter sido realizada a aplicação no desenvolvimento real, apesar dos dados serem advindos de situação real. Surge então a possibilidade de trabalho futuro no sentido de aplicar esse modelo em uma situação real. Além disso, outros estudos podem ampliar a aplicação do QFD criando um modelo conceitual para diferentes produtos têxteis e de vestuário.

\section{AGRADECIMENTOS}

Os autores agradecem aos revisores da Produção OnLine pela dedicação e contribuições para a melhoria do texto.

\section{REFERÊNCIAS}

AKAO, Y. Introdução ao desdobramento da qualidade. Tradução de Zelinda Tomie Fujikawa e Seiichiro Takahashi. Belo Horizonte: Fundação Christiano Ottoni, 1996.

AKAO, Y.; MAZUR, G. H.. The leading edge in QFD: past, present and future. International Journal of Quality \& Reliability Management, v. 20, n. 1, p. 20-35, 2003. http://dx.doi.org/10.1108/02656710310453791

ABIT - ASSOCIAÇÃO BRASILEIRA DA INDÚSTRIA TÊXTIL E DE CONFECÇÃO. Cartilha Regime Tributário Competitivo para Confecção. Brasília, 2013. Disponível em: http://www.abit.org.br/conteudo/links/publicacoes/cartilha rtcc.pdf Acesso em: 20/04/2015

ABIT - ASSOCIAÇÃO BRASILEIRA DA INDÚSTRIA TÊXTIL E DE CONFECÇÃO. Agenda de Prioridades Têxtil e Confecção 2015 a 2018. São Paulo, 2015. Disponível em: http://www.abit.org.br/conteudo/links/publicacoes/agenda site.pdf. Acesso em: 20/04/2015

ABNT - ASSOCIAÇÃO BRASILEIRA DE NORMAS TÉCNICAS. NBR 15800: vestuário referenciais de medidas do corpo humano - vestibilidade de roupas para bebê e infantojuvenil. Rio de Janeiro, 2009.

ABNT - ASSOCIAÇÃO BRASILEIRA DE NORMAS TÉCNICAS. NBR 16365: segurança de roupas infantis - especificações de cordões fixos e cordões ajustáveis em roupas infantis e aviamentos em geral - riscos físicos. Rio de Janeiro, 2015.

BERGQUIST, K.; ABEYSEKERA, J. Quality Function Deployment (QFD) - A means for developing usable products. International Journal of Industrial Ergonomics, v. 18, n. 4, p. 269-275, 1996. http://dx.doi.org/10.1016/0169-8141(95)00051-8

BRUCE, M.; DALY, L.; TOWERS, N. "Lean or agile? A solution for supply chain management in the textiles and clothing industry?" International Journal of Operations \& 
Production Management, v. 24 n. 2, p. 151-70, 2004. http://dx.doi.org/10.1108/01443570410514867

BÜYÜKÖZKAN, G.; ÇIFÇI, G. An integrated QFD framework with multiple formatted and incomplete preferences: A sustainable supply chain application. Applied Soft Computing, v. 13, n. 9, p. 3931-3941, 2013. https://doi.org/10.1016/j.asoc.2013.03.014

CARNEVALLI, J. A.; SASSI A. C.; CAUCHICK MIGUEL, P. A. Aplicação do QFD no Desenvolvimento de Produtos: levantamento sobre seu uso e perspectivas para pesquisas futuras. Gestão \& Produção, v. 1, n. 1, p. 33-49, 2004. http://dx.doi.org/10.1590/S0104$\underline{530 \times 2004000100004}$

CARNEVALLI, J.A.; CAUCHICK MIGUEL, P.A. Revisão, análise e classificação da literatura sobre o QFD - tipos de pesquisa, dificuldades de uso e benefícios do método. Gestão \& Produção, v. 14, n. 3, p. 557-579, 2007. https://doi.org/10.1590/S0104$\underline{530 \times 2007000300011}$

CHAN, L. K. ; WU, M. L. Quality function deployment: A literature review. European Journal of Operational Research, n. 143, p. 463-497, 2002. http://dx.doi.org/10.1016/S0377$\underline{2217(02) 00178-9}$

CHENG, L. C. QFD in product development: methodological characteristics and a guide for intervention. International Journal of Quality \& Reliability Management, v. 20, n. 1, p. 107-122, 2003. http://dx.doi.org/10.1108/02656710310453845

CHENG, L. C.; MELO FILHO, L. R. Desdobramento da função qualidade na gestão de desenvolvimento de produtos. São Paulo: Editora Blücher, 2007.

COPELAND, A. K; SHERMAN, S. N.; KENDEIGH, C. A.; SAELENS, B. E.; KALLWARF, H. J.. Flip flops, dress clothes, and no coat: clothing barriers to children's physical activity in child-care centers identified from a qualitative study. International Journal of Behavioral Nutrition and Physical Activity, v. 6, n. 74, 2009. http://dx.doi.org/10.1186/1479-5868-6-74

COSTA, A. C. R.; ROCHA, E. R. P. Panorama da cadeia produtiva têxtil e de confecções e a questão da inovação. BNDES Setorial, n. 29, p. 159-202, 2009.

CRISTIANO, J. J.; LIKER, J. K.; CHELSEA, C. W. Customer-driven product development through quality function deployment in the US and Japan. Journal of Production

Innovation Management, v. 17, p. 286-308, 2000. http://dx.doi.org/10.1111/1540$\underline{5885.1740286}$

DEVADASAN. S.R.; KATHIVARAN, N.; THIRUNAVUKKARASU, V. Theory and Practice of Total Quality Function Deployment: a perspective from a traditional pump-manufacturing environment. The TQM Magazine, v. 18, n. 2, p. 143-161, 2006.

http://dx.doi.org/10.1108/09544780610647865

DIAS JR, F.J.; MUNIZ JR, J.; CLARO, F.A. E.; NAKANO, D.N. Desdobramento da função qualidade (QFD) no desenvolvimento de projeto de treinamento: estudo exploratório para serviço. Produção OnLine, v. 12, n. 1, p. 91-118, 2012. http://dx.doi.org/10.14488/1676$\underline{1901 . v 12 i 1.744}$

GODOY, L.P.; CHAPOVAL NETO, A.; LORENZETT, D.B.; GUARIENTI, E.P. Melhoría contínua dos processos e combate ao desperdício através da ferramenta QFD: o caso da metalúrgica. Produção OnLine, v. 13, n.2, p. 417-449, 2013.

http://dx.doi.org/10.14488/1676-1901.v13i2.974 
GÖNDOR, V.; PATAKI, M. Designing Textile Products for the Full Life Cycle with a Special Focus on Maintenance during Usage. Acta Polytechnica Hungarica, v. 5, n. 3, p. 19-28, 2008.

GOVERS, P. M. QFD not just a tool but a way of quality management. International Journal Production Economics, n. 69, p. 151-159, 2001. http://dx.doi.org/10.1016/S0925$\underline{5273(00) 00057-8}$

HUANG, Y. Y.; BERTRAM, T. Applications of quality function deployment to apparel design in Taiwan. Journal of Fashion Marketing \& Management, v. 11, n. 2, p. 215-237, 2006. http://dx.doi.org/10.1108/13612020710751392

LAGER, T. The industrial usability of quality function deployment: a literature review and synthesis on a meta-level. R\&D Management, v. 35, n. 4, p. 409-426, 2005. http://dx.doi.org/10.1111/j.1467-9310.2005.00398.x

LIN, M. C.; WANG, C. C.; CHEN, T. C. A strategy for managing customer-oriented product design. Concurrent Engineering Research and Applications, v. 14, n. 3, p. 231-244, 2006. http://dx.doi.org/10.1177/1063293X06068390

MAY-PLUMLEE, T.; LITTLE, T. Proactive product development integrating consumer requirements. International Journal of Clothing Science and Technology, v. 18, n. 1, p. 53-66, 2006. http://dx.doi.org/10.1108/09556220610637512

MEHRJERDI, Y. Z. Quality function deployment and its extensions. International Journal of Quality \& Reliability Management, v. 27, n. 6, p. 616-640, 2010.

http://dx.doi.org/10.1108/02656711011054524

MOISESCU, E.; MANEA, L.; SUFITCHI, P. Study about 'Quality Function Deployment' method application in quality of knittings carried out on large diameter circular knitting machine analysis. Industria Textila, v. 50, n. 1, p. 21-24, 1999.

NAHM, Y. A novel approach to prioritize customer requirements in QFD based on customer satisfaction function for customer-oriented product design. Journal of Mechanical Science and Technology, v. 27, n. 12, p. 3765-3777, 2013. http://dx.doi.org/10.1007/s12206-013$\underline{0921-1}$

OKE, S. A. Manufacturing Quality Function Deployment: Literature Review and Future Trends. Engineering Journal, v. 17, n. 3, p. 79-103, 2013. http://dx.doi.org/10.4186/ej.2013.17.3.79

PARK, J. O. Middle and Elderly Women's Formal Knitwear Design Attributes Based on the Quality Function Deployment Theory. The Research Journal of the Costume Culture, v. 17, n. 3, p. 484-498, 2009.

PITIMANEEYAKUL, U.; LABAT, K. L.; DELONG, M. R. Knitwear product development process: A case study. Clothing and Textiles Research Journal, v. 22, n. 3, p. 113-121, 2004. http://dx.doi.org/10.1177/0887302X0402200302

REVELLE, J. B.; MORAN, J. W.; COX, C. A. The QFD Handbook. New York: Wiley, 1997.

SORAK, M.; UROŠEVIĆ, S.; DRAGIC, M.; SORAK, L. Improvement methodology of important clothing characteristics, by applying quality tools. Industria Textila, v. 66, n. 5, p. 283-288, 2015. 
WAISARAYUTT, C.; SIRITAWEECHAI, S. Application of quality function deployment in sport bra product development. Kasetsart Journal - Natural Science, v. 40, p. 17-180, 2006.

VEZZETTI, E.; ALEMANNI, M.; MACHEDA, J. Supporting product development in the textile industry through the use of a product lifecycle management approach: a preliminary set of guidelines. International Journal of Advanced Manufacturing Technology, v. 79, n. 9-12, p. 1493-1504, 2015. http://dx.doi.org/10.1007/s00170-015-6926-4

\section{$@ \odot$}

Artigo recebido em 22/05/2016 e aceito para publicação em 05/10/2017

DOI: http://dx.doi.org/10.14488/1676-1901.v17i4.2471 


\section{APÊNDICE A - Diagrama em árvore das qualidades exigidas}
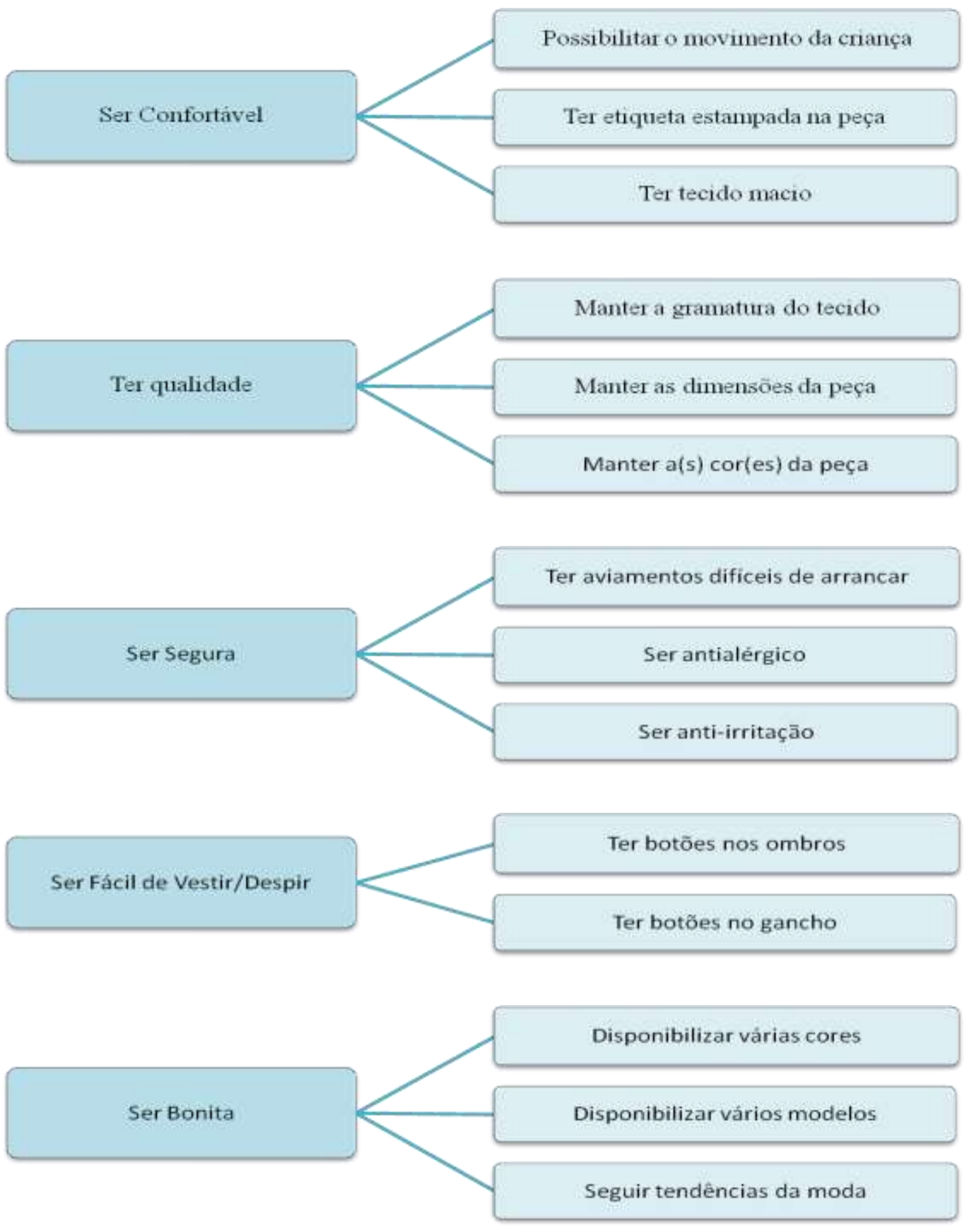

Revista Produção Online. Florianópolis, SC, v.17, n. 4, p. 1134-1159, 2017. 